\title{
PLANOS MUNICIPAIS DE EDUCAÇÃO - PERFIL DOS MUNICÍPIOS QUE NÃO POSSUÍAM PLANO MUNICIPAL DE EDUCAÇÃO NO SEGUNDO ANO DE VIGÊNCIA DA LEI N. 13.005/14
}

\author{
Gilvânia da Conceição Nascimento33 \\ Geraldo Grossi Junior ${ }^{34}$ \\ Jhonata Moreira Pereira ${ }^{35}$
}

\section{RESUMO}

Em 2009 a elaboração do PNE passou a ser uma exigência constitucional. Com as deliberações da Conferência Nacional de Educação/2010, o Governo apresentou o PL 8025/2010. Depois de tramitar por aproximadamente quatro anos no Congresso Nacional foi sanciona a Lei N. 13.005/2014. Em seu artigo oitavo determina que todos os entes federativos deveriam instituir seus planos de educação no prazo de um ano após a publicação do PNE. Houve um esforço do Ministério da Educação juntamente com a Undime e o Consed, criando a Rede de Assistência Técnica para Elaboração ou Adequação dos Planos de Educação, visando assessorar os estados, o Distrito Federal e os municípios para cumprirem esta determinação legal. A fim de prestar o melhor suporte aos entes federativos, três meios de orientação foram constituídos: organização em rede, documentos orientadores e portal eletrônico de acesso à informação. Esta pesquisa, teve como recorte somente os 49 municípios que não cumpriram a determinação legal e buscou estabelecer um perfil destes, a partir de características comuns, visando identificar os motivos que levaram ao descumprimento do preceito legal. Para esta análise, foram estabelecidas as seguintes variáveis: população; IDHM; partido político da administração municipal; e, visão dos coordenadores estaduais da rede de Assistência Técnica da SASE/MEC. Os dados analisados nos permitiram identificar que embora não exista um perfil comum para estes municípios, existem pontos de convergência que ajudam a compreender as dificuldades dos municípios para o planejamento municipal de longo prazo.

Palavras-chave: Planos de Educação. Regime de Colaboração. Perfil de Municípios.

\footnotetext{
33 Mestre em Educação. Docente da Área de Legislação e Políticas Educacionais da Universidade Estadual de Santa Cruz - UESC. Presidente da União Nacional dos Conselhos Municipais de Educação - UNCME. Membro do Fórum Nacional de Educação - FNE.

34 Mestre em Educação. Professor da rede estadual de Educação Básica do Estado de Mato Grosso. Técnico CME/Cuiabá. Membro NEPCE/EpeEM/ObsSPE/UFT. Membro do grupo de Pesquisa Federalismo e Políticas Educacionais - UFES. Assessor da UNCME MT. Assessor da UNCME Nacional. E-mail: geraldogrossi@gmail.com

35 Assistente na Diretoria de Cooperação com os Planos de Ensino da Secretaria de Articulação com os Sistemas de Ensino do Ministério da Educação - DICOPE/SASE/MEC.
} 


\title{
MUNICIPAL PLANS OF EDUCATION - PROFILE OF MUNICIPALITIES WHICH HAD NO MUNICIPAL PLAN OF EDUCATION IN THE SECOND YEAR OF EFFECTIVE LAW
}

\author{
N. $13.005 / 14$
}

\begin{abstract}
In 2009 the preparation of PNE became a constitutional requirement. With the deliberations of the National Conference of Education/2010, the Government presented the PL 8025/2010. After processing for approximately four years in the National Congress, the Law 13,005/2014 was sanctioned. In its eighth article, all federal entities should institute their education plans within one year after the publication of the PNE. There was an effort by the Ministry of Education together with Undime and Consed, creating the Technical Assistance Network for Elaboration or Adequacy of Education Plans, aiming to advise the states, the Federal District and the municipalities to comply with this legal determination. In order to provide the best support to federative entities, three means of orientation were established: network organization, guiding documents and electronic portal to information access. This research, which had as a cut only the 49 municipalities that did not comply with the legal determination and sought to establish a profile, based on common characteristics, aiming to identify the reasons that led to noncompliance with the legal precept. For this analysis, the following variables were established: population; IDHM; Political party of the municipal administration; And, view of the state coordinators of the SASE / MEC Technical Assistance network. The data analyzed allowed us to identify that although there is no common profile for these municipalities, there are points of convergence that help to understand the difficulties of municipalities for long-term municipal planning.
\end{abstract}

Keywords: Education Plans. Collaboration Regime. Profile of Municipalities.

\section{INTRODUÇÃO}

Desde a colonização do Brasil a educação passou por diversas reformas. Contudo, notamos sempre a ausência de um planejamento orgânico que pudesse garantir a elaboração e efetivação de políticas de médio e longo prazo de forma sistêmica, cobrindo todo o território nacional.

O Movimento dos Pioneiros da Educação, que em 1934 lançou o Manifesto dos Pioneiros da Educação, já apontava a necessidade da elaboração de um Plano Nacional de Educação como forma de coordenar nacionalmente a política Educacional. O Manifesto propôs um plano com sentido unitário e de bases científicas (MACHADO e GROSSI JUNIOR, 2009, p.1). 
Considerando este movimento, a Constituição Federal de 1934 coloca como obrigação da União a elaboração de Plano Nacional de Educação, in verbis:

Art 150 - Compete à União:

a) fixar o plano nacional de educação, compreensivo do ensino de todos os graus e ramos, comuns e especializados; e coordenar e fiscalizar a sua execução, em todo o território do País.

Apesar desta determinação legal, somente com o advento da Lei N. 4.024/61 (Lei de Diretrizes e Bases da Educação Nacional) é que, em 1962 , aprovou-se o primeiro Plano Nacional de Educação. Elaborado pelo Ministério da Educação e aprovado pelo Conselho Federal de Educação apresentava metas a serem alcançadas em oito anos. No entanto, ficou reduzido a uma proposta de distribuição dos recursos financeiros por níveis de ensino. (SAVIANI, 1999, p.5; MACHADO e GROSSI JUNIOR, 2009, p.1).

Já na década de 1970 foram elaborados e implantados pela União os Planos Setoriais de Educação e Cultura e recomendado aos entes federados a elaboração de seus planos. Os repasses da União para os entes federados estavam condicionados ao fato de que os planos tivessem a duração de quatro anos, fossem aprovados pelos conselhos estaduais e estivessem em consonância com as normas e critérios do planejamento nacional da educação (Art. 54 da lei n. 5692/71).

Apenas em 1988, com a aprovação da nova Constituição Federal é que a União é obrigada a elaborar Lei estabelecendo o Plano Nacional de Educação, de duração plurianual (art. 214), depois redefinido como decenal, com o objetivo de articular o sistema nacional de educação (EC 59/2009). O primeiro plano decenal de educação do Brasil nasce então em 2001 com a Lei 10.172 de 09 de janeiro de 2001. Apesar da determinação legal ser cumprida, com a elaboração e aprovação do Plano nacional de Educação, sua execução ficou seriamente comprometida por causa dos vetos que sofreu, especialmente nas questões relativas ao financiamento. 
A partir da Conferência Nacional de Educação realizada em Brasília em 2010 (CONAE/2010), nasce uma nova proposta de Plano Nacional de Educação. Esta proposta, incialmente denominada PL 8035/2010 foi de autoria do Poder Executivo levando em consideração as deliberações da CONAE. Apesar de ter recebido mais de 3.200 emendas, o espírito do PNE colocado no PL foi mantido. A partir de uma análise da Lei N. 13.005/2014 Lei do PNE 2014-2024 - podemos identificar ao menos cinco agrupamentos de metas que afirmam o espírito desse Plano Nacional de Educação.

a) No grupo 1 podemos identificar metas que são estruturantes para a garantia do direito à Educação Básica com qualidade. Podemos encontrar tais proposições nas metas 1, 2, 3, 5, 6, 7. 9, 10 e 11;

b) No grupo 2 identificamos metas que implicam na redução das desigualdades e valorização da diversidade. São as metas 4 e 8;

c) No grupo 3, identificamos metas que resguardam e indicam a valorização dos profissionais da educação. São as metas $15,16,17$ e 18;

d) No grupo 4, estão estabelecidas metas que tratam do Ensino Superior. São as metas 12, 13 e 14.

e) E no grupo 5, agrupamos as metas de gestão democrática e financiamento. São as metas 19 e 20 (BRASIL, 2014).

Em síntese, o espírito do Plano Nacional de Educação 2014 - 2024 (Lei N. 13.005/2014) está ancorado no desenvolvimento da Educação Básica e Superior (expansão e qualidade); estimula a educação como instrumento de redução das desigualdades e valorização das diversidades; estabelece a necessidade de valorização dos profissionais da educação (remuneração, formação e carreira); e define metas de ampliação e consolidação da gestão democrática da educação, além de propor ampliação do financiamento da educação (Custo aluno qualidade, 10\% d PIB para a educação, dentre outros mecanismos). 
Importante ressaltar que as metas e estratégias aprovadas no Plano Nacional de Educação (Lei N. 13.005/2014), como resultado da CONAE (Conferência Nacional de Educação) 2010 e 2014, resultaram de muitos tensionamentos durante o processo de discussão e aprovação no Congresso Nacional e nem todas as expectativas da sociedade brasileira foram contempladas na Lei. Entretanto, do ponto de vista da aprovação de um Plano de Estado para a educação brasileira, foi uma vitória importante e uma conquista construída historicamente desde o Manifesto dos Pioneiros da Educação Nova (1932).

A partir da sanção da Lei N. 13.005 de 24 de junho de 2014, que aprova o Plano Nacional de Educação - PNE e dá outras providências, o Brasil passou a ter um planejamento educacional a perdurar por dez anos, dotado de recurso financeiro proporcional ao Produto Interno Bruto-PIB. Esta configuração do PNE está prevista no art.214 da Constituição Federal de 1988, regulamentada pela Emenda Constitucional 59 de 2009.

Neste Plano, por meio da participação popular (nas conferências municipais, intermunicipais, estadual e nacional de 2010), do aval do Legislativo (aprovação do PL 8035/2010) e do Executivo (com a sanção sem veto da Lei do PNE), a sociedade brasileira determinou o que pretende que seja executado na área da educação, incluindo todos os níveis e modalidades educacionais.

Por ter previsão constitucional, este planejamento educacional passa a ser determinante na elaboração das outras peças orçamentárias da gestão pública, sejam elas: Plano Plurianual - PPA; Lei de Diretrizes Orçamentárias - LDO, Lei Orçamentária Anual - LOA e dos Planos de Trabalhos Anuais - PTA, em todos os níveis da organização governamental.

Em seu artigo $8^{\circ}$ a Lei N. 13.005/14 traz, in verbis:

Art. 8o Os Estados, o Distrito Federal e os Municípios deverão elaborar seus correspondentes planos de educação, ou adequar os planos já aprovados em lei, em consonância com as diretrizes, metas e estratégias previstas neste PNE, no prazo de 1 (um) ano contado da publicação desta Lei. 
$\S 1$ 응 Os entes federados estabelecerão nos respectivos planos de educação estratégias que:

I - assegurem a articulação das políticas educacionais com as demais políticas sociais, particularmente as culturais;

II - considerem as necessidades específicas das populações do campo e das comunidades indígenas e quilombolas, asseguradas a equidade educacional e a diversidade cultural;

III - garantam 0 atendimento das necessidades específicas na educação especial, assegurado o sistema educacional inclusivo em todos os níveis, etapas e modalidades;

IV - promovam a articulação interfederativa na implementação das políticas educacionais.

$\S 2$ o Os processos de elaboração e adequação dos planos de educação dos Estados, do Distrito Federal e dos Municípios, de que trata o caput deste artigo, serão realizados com ampla participação de representantes da comunidade educacional e da sociedade civil36 (BRASIL, 2014).

O artigo do PNE supramencionado enfatiza a necessidade de elaborar ou adequar os planos subnacionais em consonância com o Plano Nacional de Educação. Para o cumprimento deste preceito legal foi estabelecido o prazo de 01 ano, contado a partir da publicação da Lei. Desta forma, todos os entes federativos deveriam ter sancionado suas leis do plano de educação até 25 de julho de 2015.

\section{PROCESSO DE ELABORAÇÃO OU ADEQUAÇÃO DOS PLANOS DE EDUCAÇÃO SUBNACIONAIS SUGERIDO PELO MEC/SASE, UNDIME E CONSED}

O Ministério da Educação por intermédio da Secretaria de Articulação com os Sistemas de Ensino (SASE/MEC), em cumprimento de sua obrigação supletiva em relação aos estados, Distrito Federal e municípios, organizou um conjunto de atividades visando subsidiá-los no processo de elaboração ou adequação de seus planos decenais de educação. Para tanto, estabeleceu parceria com a União Nacional dos Dirigentes Municipais de Educação (UNDIME) e o Conselho Nacional de Secretários de Educação (CONSED), constituindo-se assim, um Comitê Tripartite a ser implantado em cada ente federado. A partir da constituição deste comitê, três meios de

36 Disponível em http://www.planalto.gov.br/CCIVIL_03/_Ato2011-2014/2014/Lei/L13005.htm, consultado em 25.07.2016.

Revista Exitus, Santarém/PA, Vol. 7, № 1, p. 108-130, Jan/Abr 2017. 
orientação foram constituídos, a fim de prestar o melhor suporte aos entes federativos, sejam eles: uma organização em rede, documentos orientadores e um portal eletrônico de acesso à informação.

Foi criada então a Rede de Assistência Técnica para Elaboração ou Adequação dos Planos de Educação, composta por profissionais denominados Avaliadores Educacionais - AE que residiam nos Estados e no Distrito Federal, indicados pelo Comitê Tripartite. O quantitativo de AE variava de acordo com número de municípios que o estado compunha, numa proporção, em média, de um para cada 25 municípios.

A organização desta rede contou com quatro perfis de avaliadores educacionais, sendo o Coordenador Estadual, Supervisor-Geral, Supervisor e Técnico, cada um exercendo as funções pré-determinadas pela SASE/MEC.

Os documentos orientativos basilaram, de forma metodológica, o processo de elaboração ou adequação dos planos de educação, apresentando cinco passos a serem seguidos: definir ou distribuir responsabilidades, elaborar o Documento-Base, promover um amplo debate, redigir o projeto de lei e acompanhar a tramitação no legislativo. Para acompanhar o trabalho desenvolvido em cada um dos entes federativos na elaboração ou adequação de seus planos, os cinco passos supramencionados, dissolveram-se em 10 etapas, sejam elas:

1.Sem informação - os municípios, os estados e o Distrito Federal eram classificados nesta primeira etapa durante o período em que a rede de assistência técnica não tinha nenhuma informação sobre o processo de elaboração ou adequação do plano naquele território;

2.Sem Comissão Coordenadora constituída - nesta etapa eram classificados os entes federativos que haviam sido contatos pela rede de $A E$, mas que ainda não haviam realizado a organização da comissão responsável pela realização do trabalho. Ou seja. Ainda não haviam iniciado o trabalho; 
3.Com Comissão Coordenadora instituída - Nesta etapa, o ente federado já havia constituído por meio de instrumento legal o grupo de pessoas representativas dos diversos segmentos da sociedade que teriam a responsabilidade de condução do trabalho;

4. Com diagnóstico concluído - o ente federativo migrava para esta etapa quando a comissão terminasse um levantamento das reais condições de oferta e demanda da educação no território;

5.Com documento base elaborado - a partir do diagnóstico concluído, a comissão coordenadora era orientada e elaborar um documento base contendo o próprio diagnóstico e as propostas de metas e estratégias para educação local visando a discussão da sociedade sobre este primeiro esboço de plano;

6.Com consulta pública realizada - nesta etapa estavam relacionados os entes federativos que haviam submetido 0 documento base à apreciação da sociedade através de uma consulta pública;

7.Com projeto de lei elaborado - esta etapa constituía na adequação do documento base pela comissão coordenadora, e a partir das discussões aprovadas na consulta pública de um novo documento, agora em formato de projeto de Lei;

8. Com projeto de lei enviado ao Legislativo - uma vez apresentado ao executivo, o projeto de lei (PL) deveria ser encaminhado ao legislativo para sua apreciação. Quando $O \mathrm{PL}$ já estava protocolado na casa legislativa, o ente federativo era então classificado nesta etapa;

9. Com Lei aprovada - Uma vez tramitado e aprovado no pleno do legislativo, o ente federativo passava para este status;

10. Com Lei sancionada - Por fim, após a sanção do executivo e publicação da lei o ente federativo concluía seu trabalho de 
elaboração ou adequação do Plano de Educação que é transferido para este status permanecendo assim no sistema.

A disseminação do processo em dez etapas facilitou a transparência da execução das atividades e a sociedade pôde acompanhar a evolução na construção dos planos de educação de todos os entes federativos a partir do Portal Planejando a Próxima Década, hoje denominado, Portal PNE em Movimento.

Em cada estado, o Coordenador Estadual, foi o responsável por coletar as informações quanto à alteração de etapa de cada município. Em posse dos documentos comprobatórios do cumprimento da etapa, a atualização no sistema Integrado de Monitoramento Execução e Controle SIMEC era feita.

\section{PERFIL DOS MUNICÍPIOS SEM PLANOS DE EDUCAÇÃO EM 24.06.2016}

Cessado o prazo para o cumprimento do artigo $8^{\circ}$ da Lei n 13.005/14, que aprovou o Plano Nacional de Educação a vigorar por 10 anos, e determinou o prazo de 1 (um) ano, contado a partir da publicação desta lei, para que todos os entes federativos elaborassem ou adequassem seus planos de educação, a Rede de Assistência Técnica do MEC continuou o trabalho de assessoramento aos municípios atrasados no processo.

Na data de 24 de junho de 2016, dois anos da publicação da lei do PNE, segundo o sítio www.pne.mec.gov.br, 49 municípios, ou 0,88\% do total de $5.570^{37}$ municípios brasileiros estavam sem Planos Municipais de Educação vigentes. Abaixo, segue relação dos municípios sem Lei do plano sancionada, bem como o perfil de cada um que engloba o Índice de Desenvolvimento Humano Municipal - IDHM e Quantitativo Populacional -

37 O Instituto Brasileiro de Geografia e Estatística (IBGE) atribui um código para cada município brasileiro e entres eles incluem Fenando de Noronha que um Distrito Estadual e Brasília que também tem o código de Unidade Federada enquanto Distrito Federal. Contudo a tabulação dos dados no sitio do PNE os considera também como municípios, portanto usa o mesmo quantitativo do IBGE. 
População. Cabe ressaltar que não existia nenhum município até o status $n^{\circ}$ 4 - Com Diagnóstico Concluído, ou seja, todos os entes federativos já estavam a partir do status n ${ }^{\circ} 5$ - Com Documento-Base Elaborado.

\section{Status 5. Com Documento Base Elaborado}

\begin{tabular}{llll} 
UF & MUNICÍPIO & IDHM & POPULAÇÃO \\
\hline São Paulo & $\begin{array}{l}\text { Bom Sucesso de } \\
\text { Itararé }\end{array}$ & 0,66 & 3.831 \\
\hline Minas & Patrocínio do Muriaé & 0,68 & 5.617 \\
Gerais & & & \\
\hline Bahia & Crisópolis & 0,54 & 21.617 \\
\hline Bahia & São José do Jacuípe & 0,55 & 11.061 \\
\hline Bahia & $\begin{array}{l}\text { Santa } \\
\text { Varia da }\end{array}$ & 0,61 & 41.795 \\
\hline Maranhão & São João Batista & 0,592 & 19.966
\end{tabular}

Fonte: Dos autores.

Status 6. Com consulta Pública Realizada

\begin{tabular}{|c|c|c|c|}
\hline UF & MUNICÍPIO & IDHM & POPULAÇĀO \\
\hline $\begin{array}{l}\text { Minas } \\
\text { Gerais }\end{array}$ & $\begin{array}{l}\text { Matias } \\
\text { Barbosa }\end{array}$ & 0,72 & 14.285 \\
\hline $\begin{array}{l}\text { Minas } \\
\text { Gerais }\end{array}$ & Pirapora & 0,73 & 56.229 \\
\hline São Paulo & Ubatuba & 0,75 & 86.392 \\
\hline
\end{tabular}

Fonte: Dos autores.

Status 7. Com projeto de Lei elaborado

UF MUNICÍPIO IDHM POPULAÇÃO




\begin{tabular}{|c|c|c|c|}
\hline Bahia & Feira de Santana & 0,57 & 32.640 \\
\hline Bahia & Gongogi & 0,57 & 8.082 \\
\hline Bahia & Salvador & 0,75 & 2.921 .087 \\
\hline Bahia & São Desidério & 0,71 & 617.528 \\
\hline $\begin{array}{l}\text { Espírito } \\
\text { Santo }\end{array}$ & lúna & 0,66 & 29.585 \\
\hline Goiás & $\begin{array}{l}\text { Alto Paraíso de } \\
\text { Goiás }\end{array}$ & 0,71 & 7.391 \\
\hline $\begin{array}{l}\text { Minas } \\
\text { Gerais }\end{array}$ & Juiz de Fora & 0,77 & 555.284 \\
\hline São Paulo & Cosmópolis & 0,76 & 66.807 \\
\hline São Paulo & Guarulhos & 0,76 & 1.324 .781 \\
\hline
\end{tabular}

Status 8. Com Projeto de Lei enviado ao Legislativo

\begin{tabular}{llll}
\hline UF & MUNICílPIO & IDHM & POPULAÇÃO \\
\hline Bahia & Barreiras & 0,72 & 153.918 \\
\hline Bahia & Ibiquera & 0.51 & 5.158 \\
\hline Bahia & Miguel Calmon & 0.58 & 27.536 \\
\hline Bahia & $\begin{array}{l}\text { Riacho } \\
\text { Santana }\end{array}$ & 0.61 & 36.039 \\
\hline $\begin{array}{l}\text { Espírito } \\
\text { Santo }\end{array}$ & Ibatiba & 0,64 & 25.244 \\
\hline $\begin{array}{l}\text { Minas } \\
\text { Gerais }\end{array}$ & $\begin{array}{l}\text { Conceição } \\
\text { Ipanema }\end{array}$ & 0,67 & 4.627 \\
\hline $\begin{array}{l}\text { Minas } \\
\text { Gerais }\end{array}$ & Felixlândia & 0.64 & 15.078 \\
\hline $\begin{array}{l}\text { Minas } \\
\text { Gerais }\end{array}$ & ItatiaiuçU & 0,67 & 10.781 \\
\hline
\end{tabular}




\begin{tabular}{|c|c|c|c|}
\hline $\begin{array}{l}\text { Minas } \\
\text { Gerais }\end{array}$ & Nova Lima & 0.81 & 89.900 \\
\hline $\begin{array}{l}\text { Rio de } \\
\text { Janeiro }\end{array}$ & Niterói & 0.83 & 496.696 \\
\hline $\begin{array}{l}\text { Rio de } \\
\text { Janeiro }\end{array}$ & Rio de Janeiro & 0,79 & 6.476 .631 \\
\hline $\begin{array}{l}\text { Rio de } \\
\text { Janeiro }\end{array}$ & Volta Redonda & 0,77 & 262.970 \\
\hline São Paulo & Bauru & 0.80 & 366.992 \\
\hline São Paulo & Chavantes & 0,72 & 12.484 \\
\hline São Paulo & Colômbia & 0,71 & 6.211 \\
\hline São Paulo & Gália & 0,70 & 6.894 \\
\hline São Paulo & laras & 0,67 & 7.970 \\
\hline São Paulo & Itapevi & 0.73 & 223.404 \\
\hline São Paulo & Itirapuã & 0,70 & 6.321 \\
\hline São Paulo & Lorena & 0,76 & 87.178 \\
\hline São Paulo & Louveira & 0,77 & 43.862 \\
\hline São Paulo & Marabá Paulista & 0,67 & 5.435 \\
\hline São Paulo & Matão & 0,77 & 81.439 \\
\hline São Paulo & Paraibuna & 0,71 & 18.125 \\
\hline São Paulo & Piracicaba & 0,78 & 391.449 \\
\hline São Paulo & Ribeirão Preto & 0.80 & 666.323 \\
\hline São Paulo & $\begin{array}{l}\text { Santana de } \\
\text { Parnaíba }\end{array}$ & 0,81 & 126.574 \\
\hline São Paulo & Taubaté & 0,80 & 302.331 \\
\hline São Paulo & Vargem & 0,69 & 9.854 \\
\hline
\end{tabular}

Fonte: Dos autores.

\section{Status 9. Com Lei Aprovada}

\begin{tabular}{lll}
\hline UF & MUNICÍPIO & IDHM \\
\hline
\end{tabular}




\begin{tabular}{llll}
\hline Bahia & Ruy Barbosa & 0,61 & 31.867 \\
\hline $\begin{array}{l}\text { Minas } \\
\text { Gerais }\end{array}$ & Ubaí & 0,6 & 12.397 \\
\hline
\end{tabular}

Fonte: Dos autores.

Nos dados acima apresentados (tabelas 5 a 9), observa-se que os municípios possuem perfis bastante diversificados. Há municípios pequenos, como Bom Sucesso de Itararé, com população de 3.831 habitantes e municípios de grande porte como o Rio de Janeiro, com 6.476.631 habitantes.

Com relação ao IDHM que é classificado em muito baixo (de 0 a 0,499), baixo (de 0,500 a 0,599), médio (de 0,600 a 0,699), alto (de 0,700 a 0,799 ) e muito alto (de 0,800 a 1), considerando o IDHM 2015, temos municípios com IDHM de baixo a muito alto, sendo que a maioria (28 municípios) encontram-se na faixa de alto e muito alto, vide gráfico:

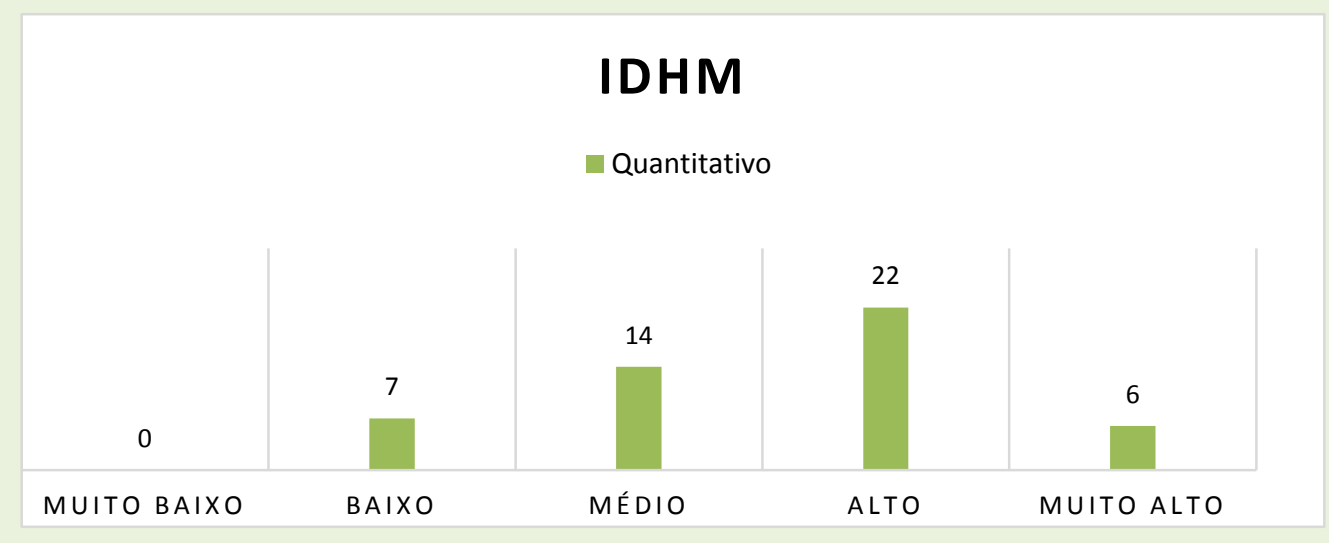

Fonte: Dos autores.

Ao dividirmos os municípios nas cinco Regiões Brasileiras, sendo elas, Norte; Sul; Centro-Oeste; Nordeste e Sudeste, obtemos a seguinte proporção de municípios sem planos de educação: 


\section{MUNICÍPIOS SEM PLANOS POR MESOREGIÃO}

Quantitativo

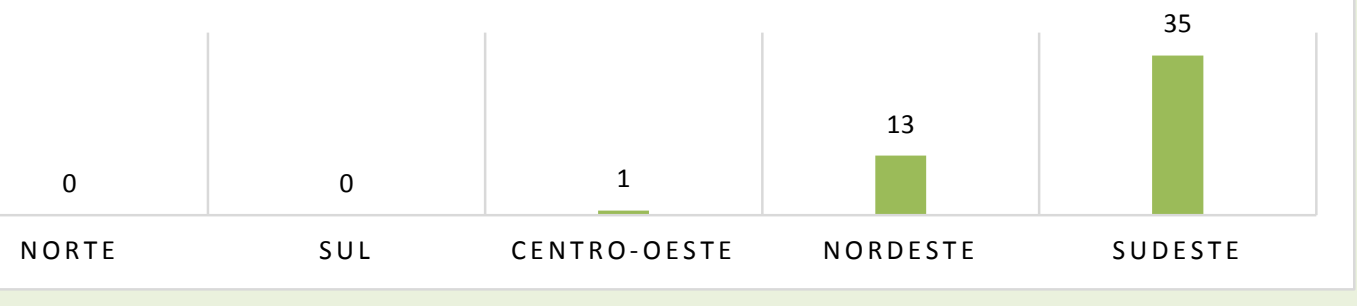

Fonte: Dos autores.

No gráfico acima apresentado, observa-se que as duas Regiões Brasileiras com um maior quantitativo de municípios sem plano são Nordeste e Sudeste. No entanto, as duas regiões vivem um contraste social, onde a primeira é a mais pobre das cinco regiões e grande parte da sua população vive em situação de subdesenvolvimento e a outra possui o maior Produto Interno Bruto - PIB do país e seus indicadores sociais como os melhores do país (TOSCANO, 2016).

Com base nos dados apresentados nas tabelas e gráficos acima, observa-se que considerando a população, o IDHM e a divisão por regiões brasileiras, há uma grande diversidade no perfil dos 49 municípios apresentados. Tal perfil engloba municípios grandes e pequenos, com IDHM alto e baixo e que compõem as regiões mais desenvolvidas e menos desenvolvidas economicamente.

Levando em consideração que segundo os indicadores estabelecidos nesta pesquisa as informações apresentadas não determinam padrão entre os municípios que não possuíam planos de educação até a data de 24 de junho de 2016, e que o Plano Nacional de Educação completou 2 anos, não é possível classificar essas características dos municípios como um possível fator para o não cumprimento do preceito legal do art. $8^{\circ}$ da Lei N.13.005/14. 
Levando em consideração o trabalho realizado junto aos municípios pelos Avaliadores Educacionais da Rede de Assistência Técnica do MEC, foi construído um questionário, a ser respondido pelo Coordenador Estadual, que visou colher a percepção desta rede quanto aos motivos que levaram ao não cumprimento do preceito legal por parte destes municípios, conforme a Tabela "A" situada no Apêndice A da presente pesquisa.

\section{AMPLIANDO A DISCUSSÃO SOBRE PLANEJAMENTO, POLÍtICAS EDUCACIONAIS E ELABORAÇÃO DOS PLANOS SUNACIONAIS DE EDUCAÇÃO}

A importância da elaboração de planos de educação no Brasil e de um Plano Nacional de Educação como articulador da política nacional de educação, remonta ao Manifesto dos Pioneiros da Educação Nova, em 1932, como perspectiva para a reconstrução educacional do Brasil: todos os nossos esforços, sem unidade de plano e sem espírito de continuidade, não lograram ainda criar um sistema de organização escolar, à altura das necessidades modernas e das necessidades do país (p.1).

Tal afirmação, se de um lado reforça a necessidade de planejamento educacional, de outro lado, nos chama a atenção para a desarticulação e fragmentação com as quais o Brasil vem tratando as políticas educacionais ao longo da sua história, caracterizadas muito mais como políticas de governo, do que como políticas de estado, inviabilizando a superação das desigualdades educacionais no território brasileiro. Portanto, pensar organicamente a educação brasileira, não faz parte da nossa tradição histórica.

Ao longo da República, o Brasil foi marcado por reformas parciais, fragmentadas, que não deram conta de pensar a complexidade da educação em toda a sua amplitude, ao tempo em que também não dialogavam com as grandes questões nacionais, relacionadas inclusive às desigualdades sociais, políticas e econômicas de uma nação em construção, tendo como consequências a descontinuidade e 
desarticulação, prejudicando a construção de um ideário educacional calcado na unidade nacional e ao mesmo tempo, nas diversidades que caracterizam o estado brasileiro, com suas singularidades e diversidades.

É possível afirmar a existência de ranços históricos que fazem com que a necessidade de planejamento e de unidade do ponto de vista das políticas educacionais, ainda sejam desafios a serem enfrentados, especialmente num contexto de país com um Pacto Federativo muito singular como o Brasil, que confere autonomia aos municípios (CF de 1988), ao tempo em que sinaliza a necessidade de Colaboração e Cooperação entre os sistemas de ensino.

Num período recente $(2010$ - 2014), as Conferências de Educação realizadas no Brasil, trouxeram com grande relevância a imperativa necessidade do Plano Nacional de Educação como articulador do Sistema Nacional de Educação. E partindo do PNE, a elaboração dos planos estaduais e municipais de educação, como forças motrizes capazes de colocá-lo em movimento. Essa perspectiva sistêmica de educação, dialoga com o Artigo 8० do Plano Nacional de Educação, quando estabelece a responsabilidade dos municípios elaborarem os seus planos municipais de educação no prazo de um ano, tendo como referência o PNE.

A Constituição de 1988, quando outorga ao município a condição de ente federado autônomo, com a possibilidade de organizar sistemas próprios de ensino, traz um novo componente à realidade educacional brasileira, que implica na necessidade urgente de planejamento articulado, que precisa dialogar então com as múltiplas realidades dos municípios brasileiros. Compreende-se então que os planos municipais a serem elaborados, devem estar em consonância com o Plano Nacional de Educação, que deverá então articular uma direção comum para a educação brasileira, tratando da unidade na diversidade, de forma a atender as particularidades regionais e territoriais dos entes federados.

Talvez seja este o grande movimento proposto pelo Ministério da Educação, quando organizou a Rede de Assistência Técnica e de 
Monitoramento, visando orientar os municípios para que tivessem os seus planos elaborados em consonância com o Plano Nacional de Educação, mas ao mesmo tempo, resguardando a autonomia do município na condução deste processo. O movimento reforçava, por um lado, a importância da descentralização e da consolidação da autonomia federativa, e por outro, a necessidade de diretrizes gerais que concedam organicidade à educação no território brasileiro.

No entanto, é visível a desarticulação dos municípios com relação a um planejamento orgânico para a educação municipal, diante das constantes alterações de rumos, reveladas nas alternâncias administrativas dos diversos governos que se revezam a cada quatro anos, inviabilizando o continuum necessário ao fortalecimento e consolidação das políticas educacionais. É comum acompanharmos mudanças espetaculares construídas na perspectiva das vontades individuais e corporativas dos grupos que se alternam no poder, resultando em desperdício de esforços e recursos públicos e aprofundamento das desigualdades regionais.

Outro aspecto essencial a ser pensado é a questão do financiamento da educação e da dependência do município em relação à União, para a condução das políticas educacionais. No modelo atual, o sistema municipal de educação (e os municípios), sofrem as consequências de uma repartição de responsabilidades, cuja conta não se alinha com os investimentos públicos transferidos aos municípios e até mesmo com a sua capacidade arrecadatória. Neste sentido, o município não costuma pensar políticas de longo prazo para a educação, detendo-se em decisões parciais e momentâneas, dentro de um contexto político-administrativo, ora favorável, ora desfavorável.

Alcançar unidade na diversidade não é uma tarefa fácil no contexto educacional brasileiro, que durante muito tempo padeceu com práticas centralizadoras e hierarquização nas relações de poder. No entanto, conquistas importantes da sociedade brasileira e avanços no sistema normativo, têm contribuído para o rompimento desta lógica excludente, 
sobre a qual se assentou a política educacional brasileira. A obra "Educação e Federalismo no Brasil: combater as desigualdades e garantir a diversidade" publicada em 2010 pela representação da UNESCO no Brasil traz um texto do professor Carlos Roberto Jamil Cury que pode contribuir com nossas reflexões:

\footnotetext{
"A Constituição de 1988, recusando tanto um federalismo centrífugo quanto centrípeto, optou por um federalismo cooperativo sob a denominação de regime articulado de colaboração recíproca, descentralizada, com funções privativas, comuns e concorrentes entre os entes federativos" (p. 158).
}

O processo de elaboração e adequação dos planos de educação no Brasil é uma realidade inconteste, a partir da aprovação do Plano Nacional de Educação (Lei N. 13005/2014). No entanto, a universalização destes planos, embora tenha se aproximado consideravelmente de cem por cento, ainda não é uma realidade. Alguns municípios, mesmo dentro de condições favoráveis e orientações comuns, não concluíram a tramitação do seu plano municipal de educação. Desafio maior ainda, será o processo de implementação, monitoramento e avaliação destes planos, nos municípios que cumpriram a determinação legal.

O momento exige do poder público e da sociedade em geral, a perspectiva dos planos de educação, como elementos indispensáveis para o enfrentamento do apartheid educacional, consolidado até então por sistemas concorrentes, desarticulados e fragmentados. Retomar o sonho dos pioneiros, com a necessária atualização histórica que o momento exige, é uma utopia possível e necessária, especialmente quando se trata do planejamento da educação brasileira.

\section{CONSIDERAÇÕES FINAIS: ENTENDENDO A PESQUISA, SEUS RESULTADOS E INCOMPLETUDES}

O artigo oitavo da Lei N. 13.005/2014 determina que todos os estados, o distrito federal e todos os municípios deveriam elaborar ou adequar seus 
Planos de Educação até a data de 24 de julho de 2015. Mesmo contando com a assistência técnica do MEC/SASE/ CONSED e UNDIME, em 25 de julho de 2016 ainda tínhamos 03 estados e 49 municípios sem planos de educação. Esta pesquisa, que teve como recorte somente os municípios que estavam na situação acima, buscou estabelecer um perfil que nos permitisse delinear um padrão dos mesmos, a partir de características comuns, visando entender os motivos que levaram ao descumprimento do preceito legal acima citado.

Para esta análise, foram estabelecidas como variáveis as seguintes:

a) População;

b) Índice de desenvolvimento Humano Municipal;

c) Partido da administração Municipal; e,

d) Visão dos coordenadores estaduais da rede de Assistência Técnica da SASE/MEC.

Os dados coletados nos permitiram as seguintes considerações: quanto à primeira variável encontramos municípios considerados de pequeno, médio e grande porte, segundo classificação do IBGE; quanto à variável Índice de Desenvolvimento Humano Municipal (IDHM), dentre as cinco classificações possíveis: muito baixo, baixo, médio, alto e muito alto, foi possível observar que nenhum dos municípios estudados se encontra na classificação "muito baixo" e todos os demais estão distribuídos entre as quatro classificações assinaladas (entre alto, médio e muito alto).

$\mathrm{Na}$ análise da variável relacionada ao partido político da administração municipal, encontramos prefeitos ligados aos seguintes partidos: PSDB, PPS, PSC, PT, PP, PSB, DEM, PDT, PMDB, PP, PR, PV, PTB, PSD, PSL e não declarado. Ou seja, não há preponderância ou exclusividade de partidos, e sim uma mescla entre eles, variando entre diversas tendências políticas. 
A quarta variável estabelecida para análise "Visão dos coordenadores estaduais da rede de Assistência Técnica da SASE/MEC", embora de caráter subjetivo, já que teve como base um questionário que visou coletar a opinião e avaliação do Coordenador Estadual da Rede sobre o processo, foi a que apresentou um elemento comum, quase que universal a todos os municípios. A maioria dos coordenadores relatou haver uma desarticulação política entre legislativo e executivo, demonstrando que processos políticos internos inviabilizaram ou dificultaram a conclusão do processo de elaboração ou adequação dos planos municipais de educação. Este resultado, encontra ancoragem nos dados que se referem às etapas que cada município conseguiu alcançar. Os gráficos 07 e 08 apontam que dos 49 municípios, 37 não foram adiante na etapa de Projeto de Lei Elaborado ou Projeto de Lei enviado ao Legislativo.

Os dados coletados e aqui analisados, de um lado, revelaram que não é possível estabelecer um perfil padrão dos municípios que não concluíram os seus planos e que, portanto, descumpriram o preceito legal estabelecido na Lei do Plano Nacional de Educação. Por outro lado, estudos ampliados e análises do contexto municipal, nos permitem inferir que a grande maioria dos municípios que cumpriram o preceito legal o fez, de um lado, pelo processo de indução externa propiciado pelo Ministério da Educação e rigorosamente organizado numa metodologia que além de colocar o município como protagonista do processo nas diversas etapas, por outro lado, destacava as possíveis consequências que poderiam advir do descumprimento deste preceito, como por exemplo, o não acesso às políticas e programas previstos no PAR (Plano de Ações Articuladas), ou implicações neste sentido, sendo este um dado que merece ser analisado com maior aprofundamento em pesquisas posteriores.

Se analisarmos o contexto de elaboração dos planos e não apenas as variáveis destacadas para este estudo, encontraremos ainda outras possibilidades que ajudam a explicar a não universalização dos mesmos, como a falta de uma cultura de planejamento nos municípios, a frágil 
participação social e a preocupação revelada por muitos gestores com relação ao financiamento, quanto ao fato de ter que fazer planos e cumprilos, mesmo num cenário de dificuldades orçamentárias. Estas são questões importantes que precisam ser mais aprofundadas, permitindo-nos análises para além das relações e disputas de poder entre Poder Executivo e Legislativo.

\section{REFERÊNCIAS}

BRASIL. CÂMARA. Projeto de Lei 8035/10, 2010.

BRASIL. Documento Final, CONAE 2010. Ministério da Educação-MEC, 2010.

BRASIL. Documento Final, CONAE 2014. Ministério da Educação-MEC, 2014.

BRASIL. Lei $n^{\circ}$ 9394, de 20 de Dezembro de 1996. Estabelece Diretrizes e Bases da Educação Nacional.

BRASIL. Constituição da República Federativa do Brasil de 1988. Brasília, 1988. Disponível em: <http://www.planalto.gov.br/ccivil_03/Constituicao/Constituicao.htm>. Acesso em: 17 out. 2016.

BRASIL. Constituição da República dos Estados Unidos do Brasil (de 16 de julho de 1934). Rio de Janeiro, 1934. Disponível em: <http://www.planalto.gov.br/ccivil_03/constituicao/Constituica034.htm>. Acesso em: 9 mai. 2016.

BRASIL. Lei n. 5.692, de 11 de agosto de 1971. Fixa Diretrizes e Bases para o ensino de $1^{\circ}$ e $2^{\circ}$ graus, e dá outras providências. Brasília, 1971. Disponível em: <http://www.planalto.gov.br/ccivil_03/leis/15692.htm>. Acesso em: 18 jan. 2016.

BRASIL. Lei n. 13.005, de 25 de junho de 2014. Aprova o Plano Nacional de Educação - PNE e dá outras providências. Brasília, 2014. Disponível em: <http://www.planalto.gov.br/ccivil_03/_ato2011-2014/2014/lei/l13005.htm>. Acesso em: 25 jul. 2016.

BRASIL. Ministério da Educação. Planejando a próxima década. Brasília, 2015. Disponível em: <http://pne.mec.gov.br/<. Acesso em: 25 jul. 2016.

IBGE. Instituto Brasileiro de Geografia e Estatística. Disponível em: <http://www.cidades.ibge.gov.br/xtras/home.php>. Acesso em: 12 set. 2016 MACHADO, M. M.; GROSSI JUNIOR, G. A Educação de Jovens e Adultos no Plano Nacional de Educação e nos Planos Estaduais de Educação. In: XXIV Simpósio Brasileiro e III Congresso Interamericano de Política e Administração 
da Educação, 2009, Vitotia. Cadernos ANPAE. Vitória: UFES/CE/PPGE, 2009. v. 01. p. 235-235.

OLIVEIRA, R. P.; SANTANA, W. (orgs). Educação e Federalismo no Brasil: combater as desigualdades e garantir a diversidade. Brasília: UNESCO, 2010.

SAVIANI, D. Sistemas de ensino e planos de educação: o âmbito dos Municípios. Educação \& Sociedade, Campinas, a. XX, n. 69, p. 119-136, dez. 1999. Disponível em: <http://www.scielo.br/pdf/es/v20n69/a06v2069.pdf>. Acesso em: 18 jan. 2016.

TOSCANO, F. $(25$ de 08 de 2016). Portal Brasil. Disponível em: <http://www.portalbrasil.net/contatos.htm>

Recebido em: Setembro de 2016 Aceito em: Dezembro de 2016 


\section{APÊNDICE A - Questionário destinado aos Coordenadores Estaduais}

Na sua opinião, qual foi o principal motivo para que o município não tenha concluído o trabalho? (Se desejar assinalar mais de uma opção favor numerá-las em ordem crescente de importância, ou seja, a que mais influenciou seria a opção marcada com o número 01 , e assim sucessivamente):

( ) Desinteresse da gestão municipal (aqui entendido como prefeito)

( ) Desinformação da gestão municipal (aqui entendido como prefeito)

( ) Desinteresse da gestão municipal (aqui entendido como Dirigente Municipal de Educação)

( ) Desinformação da gestão municipal (aqui entendido como Dirigente Municipal de Educação)

( ) Incapacidade técnica da equipe municipal

( ) Desarticulação política entre legislativo e executivo

( ) Falta de participação da sociedade civil

( ) Outros

Informações complementares: 